\title{
Low level of 5-Hydroxymethylcytosine predicts poor prognosis in non-small cell lung cancer
}

\author{
YUNFEI LIAO ${ }^{1,2 *}$, JIE GU $^{2 *}$, YONGBING WU $^{1 *}$, XIANG LONG ${ }^{1}$, DI GE ${ }^{2}$, JIANJUN XU $^{1}$ and JIANYONG DING ${ }^{2}$ \\ ${ }^{1}$ Department of Cardiothoracic Surgery, The Second Affiliated Hospital of Nanchang University, Nanchang, Jiangxi 330000; \\ ${ }^{2}$ Department of Thoracic Surgery, The Affiliated Zhongshan Hospital of Fudan University, Shanghai 200032, P.R. China
}

Received March 11, 2015; Accepted March 18, 2016

DOI: $10.3892 / \mathrm{ol} .2016 .4474$

\begin{abstract}
The loss of 5-hydroxymethylcytosine (5-hmC) has previously been demonstrated to be implicated in the initiation and progression of various tumors. However, its role in non-small cell lung cancer (NSCLC) remains unknown. The present study aimed to determine the level of 5-hmC in NSCLC and their adjacent normal lung tissues by immunohistochemistry and dot-blot analysis; then the relationship between 5-hmC level and the clinicopathological features of NSCLC and the prognostic significance of 5-hmC level in NSCLC patients were analyzed. By employing the dot-blot analysis, a significant reduction of 5-hmC level in NSCLC tissues compared with the adjacent normal tissues was detected, which were further verified by the immunohistochemistry results on tissue microarrays. Further analyses demonstrated that $65.38 \%$ (136/208) presented with low 5-hmC level, and low 5-hmC level was significantly associated with lymph node metastasis $(\mathrm{P}<0.001)$, histological type $(\mathrm{P}<0.001)$ and large tumor size $(\mathrm{P}=0.031)$. Notably, the 5-year overall survival rate of patients with low 5-hmC levels were significantly lower than patients with high 5 -hmC levels $(\mathrm{P}<0.001)$. In addition, it was demonstrated that 5-hmC level was identified as independent prognostic
\end{abstract}

Correspondence to: Mr. Jianyong Ding, Department of Thoracic Surgery, The Affiliated Zhongshan Hospital of Fudan University, 180 Fenglin Road, Shanghai 200032, P.R. China

E-mail: dingjianyongmd@163.com

Mr. Jianjun Xu, Department of Cardiothoracic Surgery, The Second Affiliated Hospital of Nanchang University, 1 Minde Road, Nanchang, Jiangxi 330000, P.R. China

E-mail: jianjxu@126.com

*Contributed equally

Abbreviations: NSCLC, non-small cell lung cancer; 5-mC, 5-methylcytosine; 5-hmC, 5-hydroxymethylcytosine; DNMTs, DNA methyltransferases; TET, ten-eleven translocation; TNM, tumor-lymph-node metastasis; OS, overall survival; TMAs, tissue microarrays

Key words: 5-Hydroxymethylcytosine, non-small cell lung cancer, epigenetic modification, prognosis, biomarker factor in patients' overall survival. In conclusion, downregulation of 5-hmC may serve as a useful biomarker for NSCLC prognosis evaluation.

\section{Introduction}

Lung cancer is a common and very serious type of cancer, is one of the major causes of cancer related mortality worldwide (1), and $>80 \%$ of lung cancer cases are non-small cell lung cancer (NSCLC) (2). Although there have been improvements in diagnostic approaches and the introduction of novel therapeutic agents during the last decades, the 5-year survival rate of lung cancers remains low due to high recurrence rates and early metastasis (3). Thus, it is important and urgent to identify novel markers to predict NSCLC recurrence and metastasis.

5-methylcytosine $(5-\mathrm{mC})$ is a usual epigenetic modification in mammalian DNA, and the process of cytosine converting to $5-\mathrm{mC}$ is catalyzed by DNA methyltransferases (DNMTs) (4). In mammals, the ten-eleven translocation (TET) family proteins can hydroxylate 5-mC to 5-hydroxymethylcytosine (5-hmC) (5), which can be further oxidized to produce 5-formylcytosine (5-fC) and 5-carboxylcytosine (5-caC), which is finally be corrected by thymine DNA glycosylase (TDG) (6). Generally, this circulation of cytosine methylation and demethylation exists in all kinds of elementary processes in mammalian cells, such as genome stability and imprinting (7). As an intermediate in DNA demethylation processes, 5-hmC is considered to serve an important role in the diagnosis and prognosis prediction of several malignant tumors; for example, the loss of 5-hmC has been reported to be involved in intrahepatic cholangiocarcinoma (ICC) and gastric cancer progression, and high levels of 5 -hmC are associated with favorable prognosis in hepatocellular carcinoma (HCC) (8). Notably, a previous study has indicated that the loss of 5-hmC was implicated in the onset of malignant cellular transformation, and may serve as an epigenetic hallmark of a number of types of cancer (9). Although the importance of 5-hmC in cancer has been established, its role and clinical significance in NSCLC remain to be determined.

The present study aimed to determine the level of 5-hmC in NSCLC and their adjacent normal tissues, and then detected the 5-hmC level by immunohistochemistry in NSCLC tissue microarrays. In addition, the relationship between the 5-hmC 
level and the NSCLC clinical and pathological characteristics were analyzed. Finally, the clinical value of $5-\mathrm{hmC}$ in NSCLC was also determined.

\section{Patients and methods}

Patients and specimens. All specimens were obtained from 208 NSCLC patients who received curative resection at Zhongshan Hospital of Fudan University (Shanghai, China) in 2005. The collection and conservation of samples and details of the cohort are in agreement with the description of our previous study (10). Briefly, tumor stage was adjudged on the basis of the tumor node metastasis (TNM) 7th edition of International Union Against Cancer Staging Manual (11). Pathological classification was ruled according to the World Health Organization criteria (12). The follow-up was terminated in July 2010. The median follow-up period was 43 months (range, 1-66 months). The overall survival (OS) was defined as the interval between surgery and death or between surgery and the last observation for surviving patients. Ethical approval was obtained from the Zhongshan Hospital Research Ethics Committee, and written consent was obtained from all patients.

Dot-blot analysis. Dot-blot protocol was described elsewhere (8). In brief, total DNA was denatured with $0.4 \mathrm{M}$ $\mathrm{NaOH}, 10 \mathrm{mM}$ EDTA at $99^{\circ} \mathrm{C}$ for $5 \mathrm{~min}$ and then neutralized by adding an equal volume of cold $2 \mathrm{M}$ ammonium acetate ( $\mathrm{pH}$ 7.0). An equal value of genomic DNA was then spotted on nitrocellulose membranes ( $2 \mu \mathrm{l}$ per spot; $150 \mathrm{ng} / \mu \mathrm{l})$. After ultraviolet cross-linking, membranes were blocked $1 \mathrm{~h}$ with 5\% BSA in TBST and then incubated with mouse monoclonal anti-5-hmC antibody (1:10,000; catalog no., 39999; Active Motif, La Hulpe, Belgium) overnight at $4^{\circ} \mathrm{C}$ and followed subjecting to western blotting detection. The protocol of western blotting was described elsewhere (13).

Tissue microarrays and immunohistochemistry. Tissue microarrays (TMAs) were established by Shanghai Biochip Co. Ltd (Shanghai, China) and are described in our previous study (10). Immunohistochemistry was performed according to our previous study (14). In brief, the slides were dewaxed at $65^{\circ} \mathrm{C}$ for $2 \mathrm{~h}$, followed by washing with xylene, rehydrating in ethanol, and then endogenous peroxidase activity was blocked in $3 \% \mathrm{H}_{2} \mathrm{O}_{2}$ for $15 \mathrm{~min}$. Antigen retrieval was performed by heating the samples at $100^{\circ} \mathrm{C}$ for $20 \mathrm{~min}$ in $10 \mathrm{mmol} / \mathrm{l}$ sodium citrate ( $\mathrm{pH}$ 6.0). Then, after cooling to room temperature, the TMA slides were placed in $2 \mathrm{M} \mathrm{HCl}$ for $30 \mathrm{~min}$, rinsed in PBS buffer, and further placed in $100 \mathrm{mM}$ Tris- $\mathrm{HCl}(\mathrm{pH} \mathrm{8.0)}$ for $10 \mathrm{~min}$. They were then incubated in 5\% BSA at room temperature for $60 \mathrm{~min}$ to reduce nonspecific reactions. Subsequently, the slides were incubated overnight at $4{ }^{\circ} \mathrm{C}$ with rabbit monoclonal anti-5-hmC antibody $(1: 10,000)$. Then the slides were incubated with goat polyclonal anti-mouse IgG2a-hydrogen peroxidase conjugated secondary antibody (1:2000; catalog no., ab97245; Abcam, Cambridge, UK) for $60 \mathrm{~min}$ at $37^{\circ} \mathrm{C}$ and stained with diaminobenzidine- $\mathrm{H}_{2} \mathrm{O}_{2}$ (Beyotime Institute of Biotechnology, Haimen, China). Finally, the TMA slides were counterstained with hematoxylin (Sigma-Aldrich, St. Louis, MO, USA), dehydrated, and mounted with a cover slip using a neutral resin.
Evaluation of immunostaining intensity. The 5-hmC was immunohistochemically stained yellow or brown located in the cell nucleus. The method for judging immunohistochemical staining was described elsewhere (8). Briefly, the samples were scored independently according to the intensity of cellular staining and the proportion of stained cells. The proportion of stained cells in total cell number of every point about $\leq 25 \%$, 25 to $50 \%, 50$ to $75 \%,>75 \%$ were scored as $0,1,2,3,4$ points, respectively. The intensity of cellular staining was determined by the degree of color, namely none, weak (yellow), medium (brown), and strong (dark brown) were scored as $0,1,2,3$ points, respectively. The final additive score of $0-1,2-3,4-5$ and 6-7 points were divided into negative (-), weak positive (+), moderate positive $(++)$ and strong positive $(+++)$, respectively. The negative and weak positive staining were defined as the low level group, and the moderate positive and strong positive staining were defined as the high level group of 5-hmC level, respectively.

Statistical analysis. Statistical analyses were handled using the SPSS 17.0 software package (SPSS Inc., Chicago, IL, USA). OS was calculated using the Kaplan-Meier method and was analyzed using the log-rank test. A Cox proportional hazards regression model was used to analyze independent prognostic factors. For comparisons of individual variables, $t$-tests, chi-square tests, Fisher exact tests, and Spearman coefficient tests were used when necessary. Statistical significance was determined for 2-tailed tests at $\mathrm{P}<0.05$.

\section{Results}

The 5-hmC level was significantly down-regulated in NSCLC tissues. The level of 5-hmC in NSCLC and their adjacent lung tissues in the same slides were detected by immunohistochemical staining. As presented in (Fig. 1A), after identification of NSCLC and normal lung tissues by hematoxylin and eosin (H\&E) staining, it was observed that the staining of 5-hmC was located in the nucleus, and the level of 5-hmC in NSCLC tissues was lower than that in the adjacent normal lung tissues, the difference was significant $(\mathrm{P}<0.05)$ as was observed in a previous report in HCC (8). Furthermore, the dot-blot analysis also supported the results from the immunochemical analysis (Fig. 1B). The above results indicate that the loss of 5-hmC may be involved in the onset and progression of NSCLC.

TMAs analysis and clinicopathological features. The difference in 5-hmC levels were determined between NSCLC tissues and the corresponding para-tumor tissues using a tissue microarray technique. The results demonstrated that the overall level of 5-hmC in NSCLC tissues was markedly lower than that in matched adjacent normal tissues. Fig. 2A presents representative photos including H\&E and immunohistochemical staining to highlight the difference. Notably, we also observed a phenomenon that several levels of 5-hmC simultaneously came in the results of NSCLC tissues and paired adjacent normal tissues (Fig. 2B).

Subsequently, the clinicopathological features of NSCLC in this cohort were analyzed. A total of 208 cases of primary NSCLC were involved in this analysis, the cohort contained 148 males and 60 females, and 85 squamous cell carcinoma, 

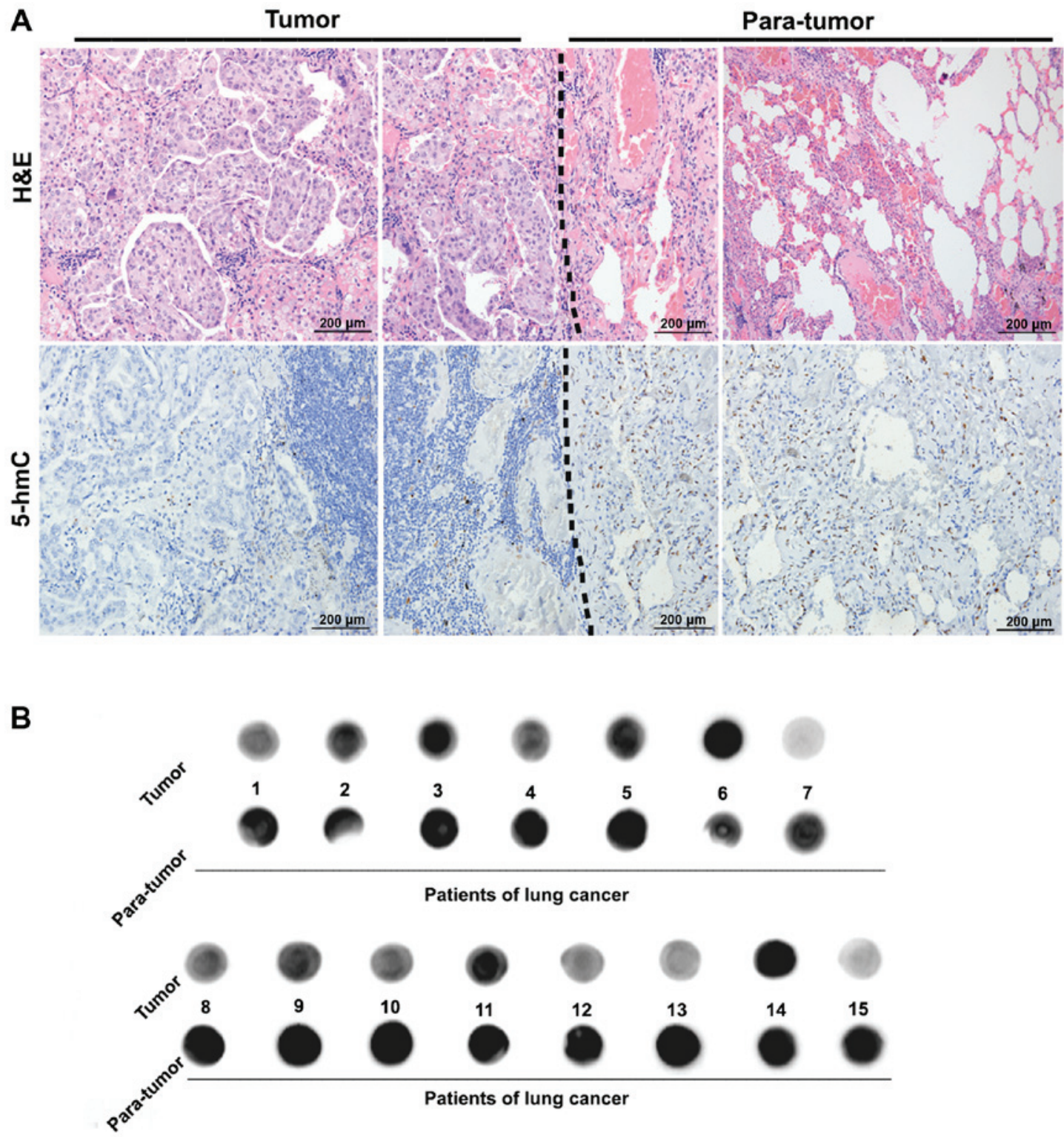

Figure 1. The 5-hmC level was down-regulated in NSCLC tissues. (A) Immunohistochemical staining showed that 5-hmC level was significantly lower in NSCLC tissues compared with adjacent normal tissues. (B) Dot blot analysis showed the levels of 5-hmC in 15 pairs of NSCLC and adjacent normal tissues. 5-hmC, 5-hydroxymethylcytosine; NSCLC, non-small cell lung cancer; H\&E, hemotoxylin and eosin.

110 adenocarcinomas and 13 other pathologic subtypes of NSCLC (including adenosquamous carcinoma, large-cell carcinoma, mucoepidermoid carcinoma and carcinosarcoma). A total of 144 tumors were in TNM stages I-II and 64 tumors were in stages III-IV. In addition, 93 tumors were low differentiation, and 115 tumors were highly differentiated. The statistical details about patients and the association between 5-hmC level and the clinicopathological features are displayed in Table I.

Association between 5-hmC level and the clinicopathological parameters of NSCLC. The relationship between the clinicopathological parameters of NSCLC and 5-hmC levels were analyzed, and it demonstrated that a low level of 5-hmC accounted for $65.38 \%(136 / 208)$ specimens from NSCLC patients $(\mathrm{P}<0.001$, Fig. 3A). Furthermore, the 5-hmC level was significantly associated with lymph node metastasis $(\mathrm{P}<0.001)$, histological type $(\mathrm{P}<0.001)$ and tumor size $(\mathrm{P}=0.031)$. NSCLC patients with lymph node metastases had significantly higher proportion of low 5-hmC level than those without lymph node metastases (Fig. 3B). Particularly, this high proportion of low 5-hmC level was more strongly associated with squamous cell carcinomas than with adenocarcinomas (Fig. 3C). Notably, a high proportion of low 5-hmC level was also present in tissues with large tumor size (Fig. 3D). The patients with a high proportion of low 5-hmC level possessed a more unfavorable prognosis compared with the patients with a low proportion of low 5-hmC level (Fig. 3E-G). However, other clinicopathological features, including age, smoking status, were not directly associated with the level of 5-hmC.

Low level of 5-hmC was correlated with poor prognosis of NSCLC. During the following-up, 120 patients succumbed to recurrence or metastasis of disease. The 5-year OS rate after surgery for all patients was $47.6 \%$. The 5-year OS rate for patients with low 5-hmC level was significantly lower than 
A

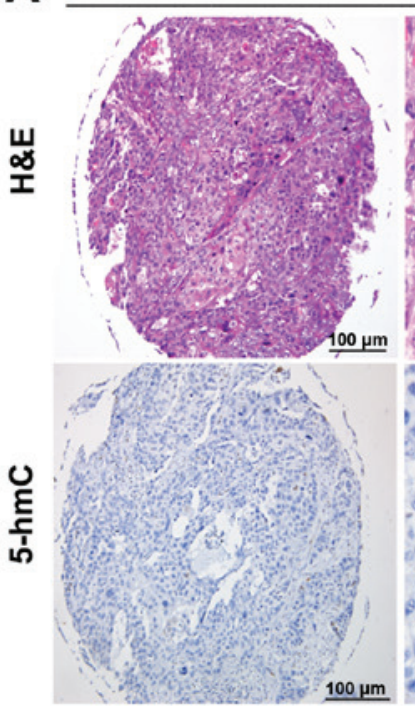

Tumor

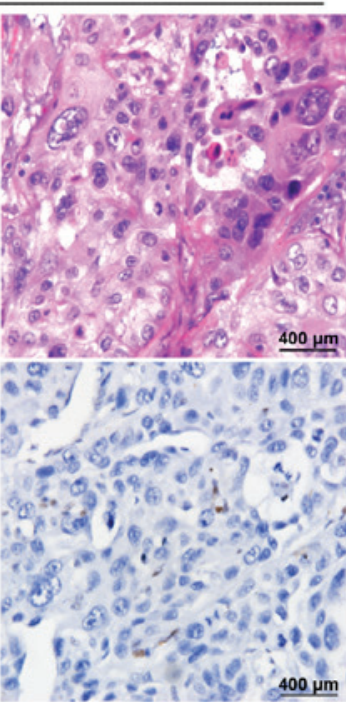

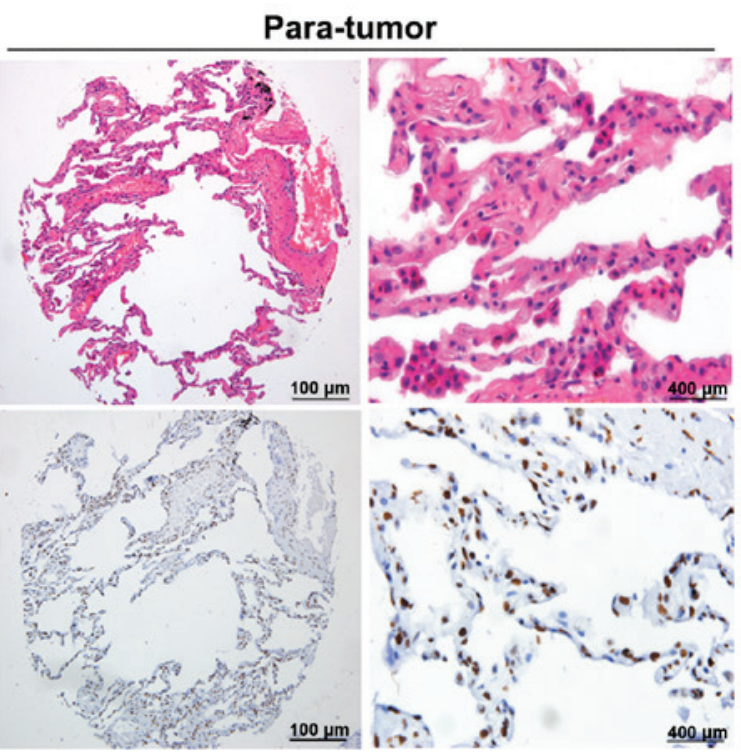

B Negative

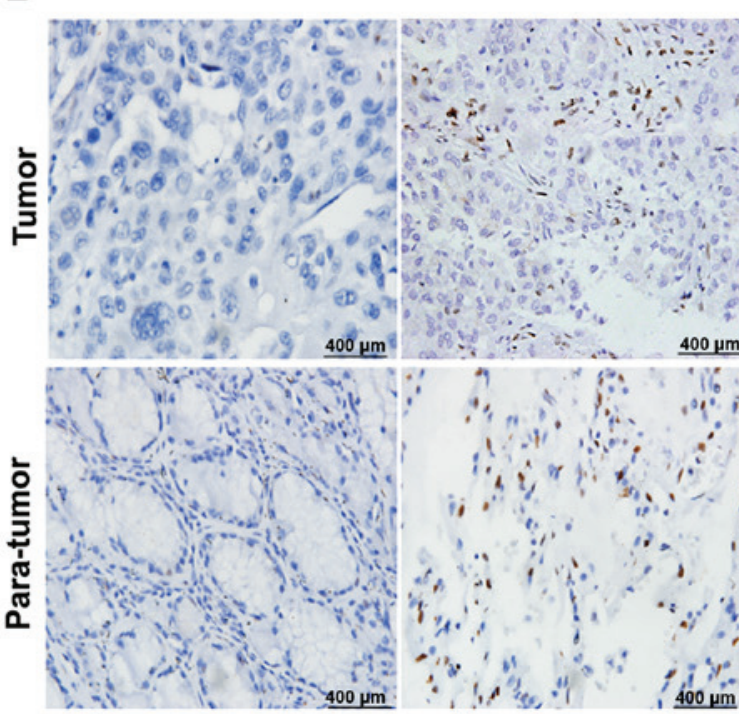

Low Moderate

\section{Strong}

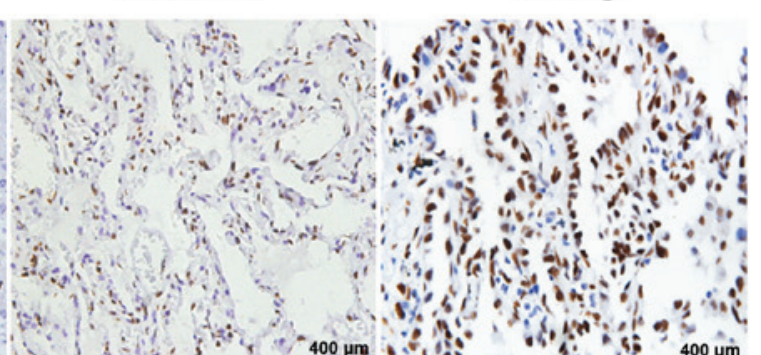

$00 \hat{\mathrm{m}}$

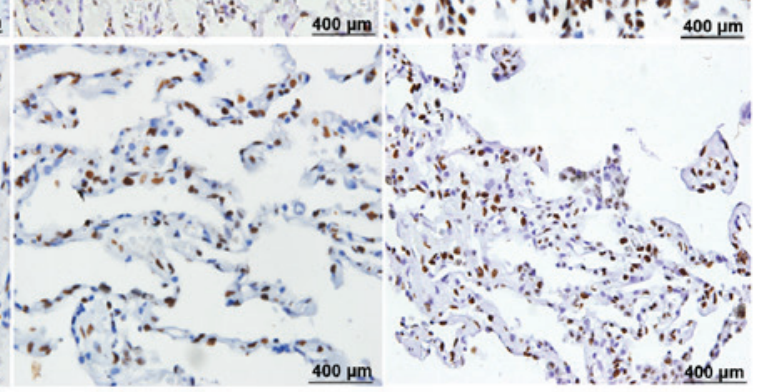

Figure 2. Representative pictures of 5-hmC staining using TMAs. (A) Representative pictures of 5-hmC staining in NSCLC and adjacent para-tumor tissues using TMAs technique. (B) Various levels of 5-hmC staining in NSCLC and adjacent para-tumor tissues. 5-hmC, 5-hydroxymethylcytosine; NSCLC, non-small cell lung cancer; H\&E, hemotoxylin and eosin; TMA, tissue microarrays.

patients with high 5-hmC level ( $\mathrm{P}<0.001$, Fig. 4A). In order to determine the effect exerted on the tumors of corresponding patients of different 5 -hmC levels, the 208 patients were divided into 3 groups according to the difference in the intensity of immunostaining between tumors and their matched adjacent tissues in TMAs. The $\mathrm{T}<\mathrm{N}$ group, whose immumostaining intensity was significantly lower in tumor tissues compared with the paired peritumors, had the worst OS rate. By contrast, the $\mathrm{T}>\mathrm{N}$ group with a higher immunostaining intensity in the tumor tissues compared with the matched para-tumor possessed a better prognosis than the other groups ( $\mathrm{T}>\mathrm{N}$ vs. $\mathrm{T}=\mathrm{N} ; \mathrm{P}=0.021$; Fig. 4B). As the 5 -hmC levels were different between the squamous cell carcinoma and adenocarcinomas, a subgroup analysis by pathological subtype was performed. In squamous cell carcinoma and adenocarcinomas, the association remained significant $(\mathrm{P}=0.046$ and $\mathrm{P}=0.011$, respectively) (Fig. 4C and D). These data further revealed that low 5-hmC levels may predict a poor prognosis of NSCLC patients.

Univariate and multivariate analyses of predictive factors of OS for patients. Univariate analysis revealed that tumor size ( $\geq 3 \mathrm{~cm}$ ), lymph node metastasis, high TNM stage, poor differentiation and low 5-hmC level were associated with a shorter OS. Univariate analysis revealed that tumor size $(\geq 3 \mathrm{~cm}$; $\mathrm{P}<0.001)$, lymph node metastasis $(\mathrm{P}<0.001)$, high TNM stage $(\mathrm{P}<0.001)$, poor differentiation $(\mathrm{P}<0.001)$ and low 5-hmC level $(\mathrm{P}<0.001)$ were associated with a shorter OS rate. In multivariate analysis, tumor size $(\mathrm{P}=0.003)$, lymph node metastasis $(\mathrm{P}=0.050)$, tumor stage $(\mathrm{P}=0.034)$ and 5 -hmC level $(\mathrm{P}=0.014)$ were identified as independent prognostic factors in patients' OS rate (Table II). 
Table I. Correlation between 5-hmC and clinicopathological characteristics in 208 NSCLCs.

\begin{tabular}{|c|c|c|c|c|}
\hline \multirow[b]{2}{*}{ Variables } & \multirow[b]{2}{*}{ No. of patients } & \multicolumn{2}{|c|}{ 5-hmC level } & \multirow[b]{2}{*}{ P-value } \\
\hline & & Low & High & \\
\hline Age & & & & 0.468 \\
\hline$<60$ & 102 & 64 & 38 & \\
\hline$\geq 60$ & 106 & 72 & 34 & \\
\hline Gender & & & & 0.004 \\
\hline Male & 148 & 106 & 42 & \\
\hline Female & 60 & 30 & 30 & \\
\hline Smoking status & & & & 0.140 \\
\hline Smoker & 84 & 60 & 24 & \\
\hline Non-smoker & 124 & 76 & 48 & \\
\hline Histological type & & & & $<0.001^{\mathrm{b}}$ \\
\hline Squamous cell carcinoma & 85 & 71 & 14 & \\
\hline Adenocarcinoma & 110 & 55 & 55 & \\
\hline Other $^{\mathrm{a}}$ & 13 & 10 & 3 & \\
\hline Tumor stage & & & & 0.059 \\
\hline I-II & 144 & 88 & 56 & \\
\hline III-IV & 64 & 48 & 16 & \\
\hline Lymph node metastasis & & & & $<0.001$ \\
\hline Yes & 90 & 71 & 19 & \\
\hline No & 118 & 65 & 53 & \\
\hline Tumor size & & & & 0.031 \\
\hline$<3 \mathrm{~cm}$ & 69 & 38 & 31 & \\
\hline$\geq 3 \mathrm{~cm}$ & 139 & 98 & 41 & \\
\hline Differentiation & & & & 0.381 \\
\hline Well/moderate & 115 & 72 & 43 & \\
\hline Poor & 93 & 64 & 29 & \\
\hline
\end{tabular}

Bold values are statistically significant $(\mathrm{P}<0.05)$. ${ }^{2}$ Other including adenosquamous carcinoma, large-cell carcinoma, mucoepidermoid carcinoma

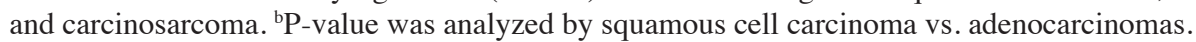

Table II. Univariate and multivariate analysis of factors associated with OS.

\begin{tabular}{|c|c|c|c|c|c|c|}
\hline \multirow[b]{2}{*}{ Variables } & \multicolumn{3}{|c|}{ Univariate analysis } & \multicolumn{3}{|c|}{ Multivariate analysis } \\
\hline & HR & $95 \% \mathrm{CI}$ & P-value & HR & $95 \% \mathrm{CI}$ & P-value \\
\hline Gender (male vs. female) & 0.789 & $0.526-1.183$ & 0.251 & & & \\
\hline $\begin{array}{l}\text { Smoking status } \\
\text { (non-smokers vs. smokers) }\end{array}$ & 1.284 & $0.895-1.843$ & 0.175 & & & \\
\hline Tumor size ( $\geq 3 \mathrm{~cm}$ vs. $<3 \mathrm{~cm})$ & 2.755 & $1.758-4.318$ & $<0.001$ & 2.019 & $1.269-3.211$ & 0.003 \\
\hline Lymph node metastasis (yes vs. no) & 3.042 & $2.103-4.399$ & $<0.001$ & 1.902 & $1.210-2.989$ & 0.005 \\
\hline Tumor stage (III-IV vs. I-II) & 2.771 & $1.922-3.993$ & $<0.001$ & 1.611 & $1.036-2.506$ & 0.034 \\
\hline $\begin{array}{l}\text { Differentiation } \\
\text { (well/moderate vs. poor) }\end{array}$ & 1.431 & $1.000-2.049$ & 0.050 & 1.202 & $0.833-1.735$ & 0.325 \\
\hline 5-hmC level (low vs. high) & 0.476 & $0.315-0.720$ & $<0.001$ & 0.589 & $0.386-0.897$ & 0.014 \\
\hline
\end{tabular}

OS, overall survival; 95\% CI, 95\% confidence interval. Variables were adopted for their prognostic significance by univariate analysis with forward stepwise selection (forward, likelihood ratio). Variables were adopted for their prognostic significance by univariate analysis $(\mathrm{P}<0.05)$. 
A

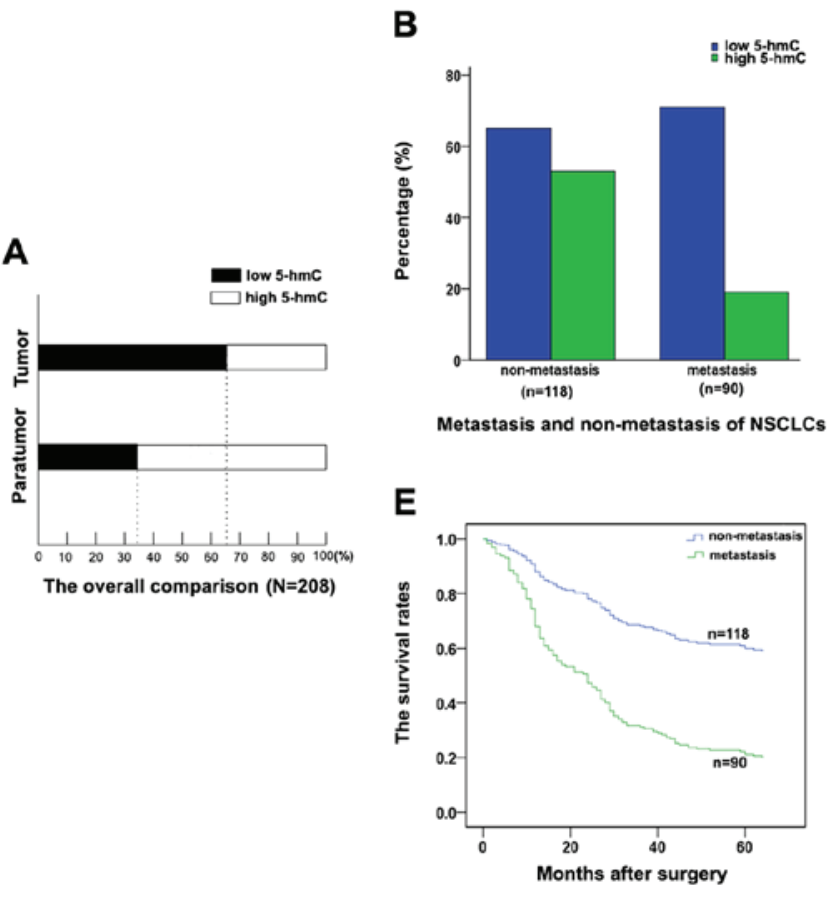

C

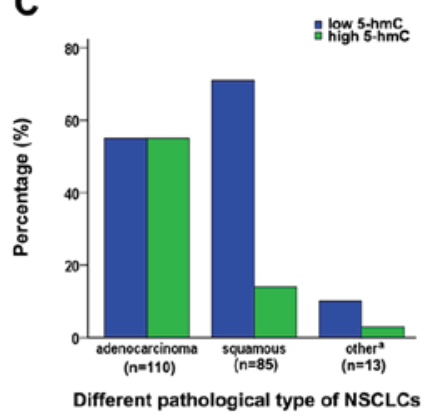

$\mathbf{F}$

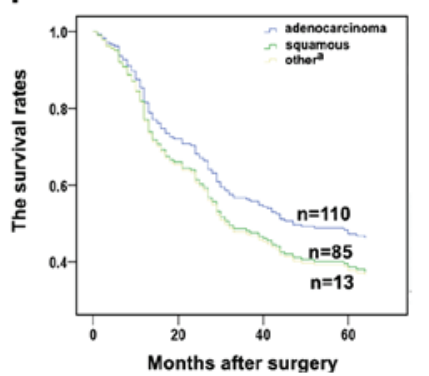

D

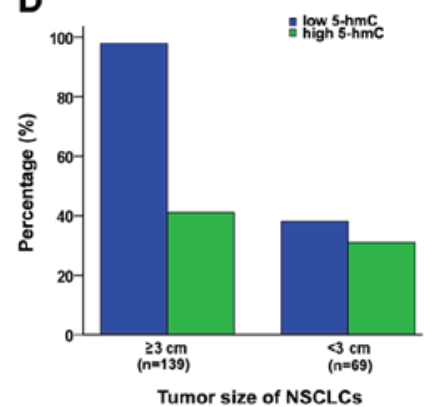

Tumor size of NSCLCs

G

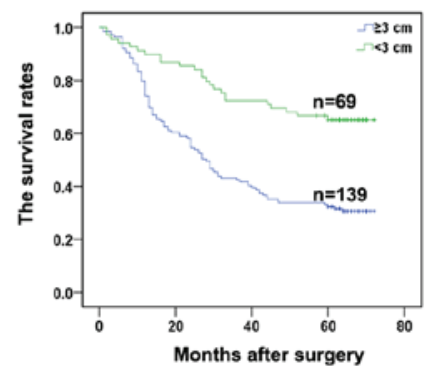

Figure 3. The 5-hmC level in subtypes of NSCLC. (A) The histogram of 5-hmC level in TMAs including 208 NSCLC and their adjacent tissues. (B) The bar graph of 5-hmC level in NSCLC tissues with lymph node metastasis or without metastasis. (C) 5-hmC level in different pathaological types of NSCLC tissues. (D) 5-hmC level in different tumor sizes of NSCLC tissues. (E) Kaplan-Meier survival curves of patients with lymph node metastasis or without metastasis. (F) Kaplan-Meier survival curves of patients with different pathaological types of NSCLC. (G) Kaplan-Meier survival curves of patients with different tumor sizes. 5-hmC, 5-hydroxymethylcytosine; NSCLC, non-small cell lung cancer; TMA, tissue microarrays.

A

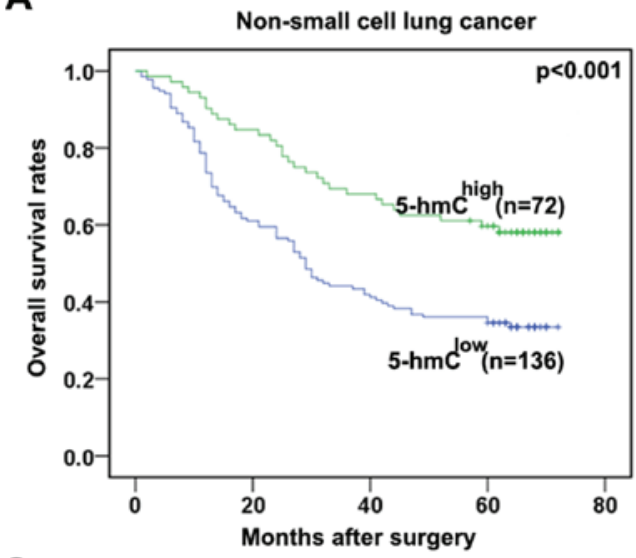

C

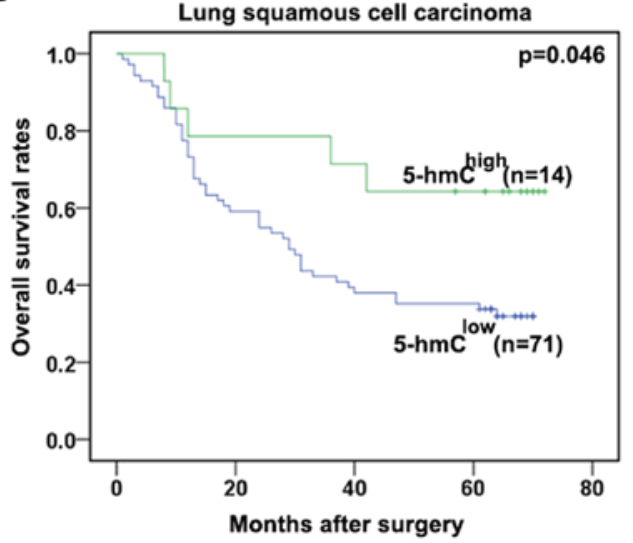

B

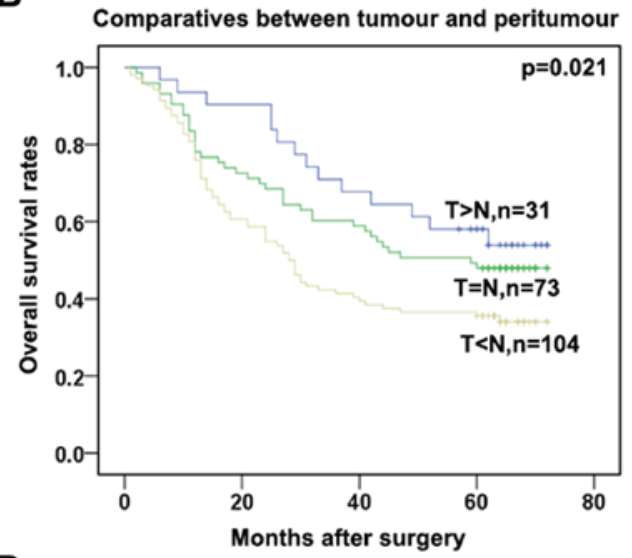

D

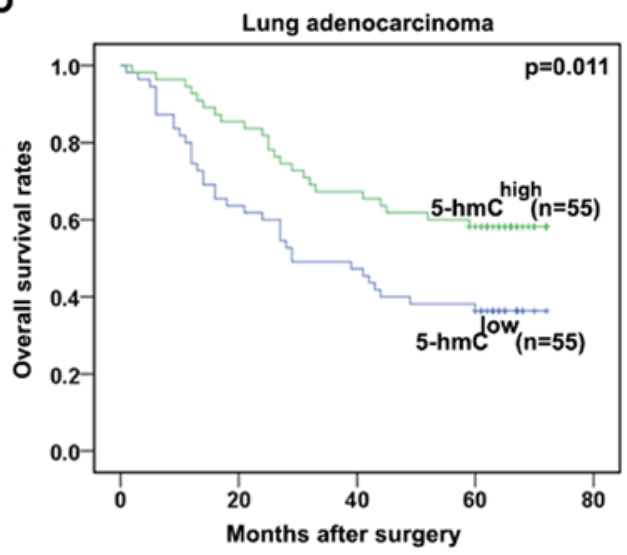

Figure 4. Prognostic significance assessed by Kaplan-Meier Survival estimates. (A) Comparisons of OS by 5-hmC level in NSCLC. (B) Comparisons of OS in three different groups classified according to the comparison of immunohistochemical staining intensity in the tumor tissues and adjacent normal tissues of the same patient. (C) Comparisons of OS by 5-hmC level in lung squamous cell carcinoma. (D) Comparisons of OS by 5-hmC level in lung adenocarcinoma. OS, overall survival; 5-hmC, 5-hydroxymethylcytosine; NSCLC, non-small cell lung cancer. 


\section{Discussion}

5-hmC, as the hydroxylated form of 5-mC, was first discovered in T-even phage DNA in 1952 (15). A previous study indicated that 5 -hmC was associated with diseases such as nerve disorders, leukemia and tumors (16). In recent years, 5-hmC has become more extensively studied. Previous studies have reported its position and prognostic value in a variety of tumors (17). However, the relationship between 5-hmC level and the progression of lung cancer and prognosis of patients with lung cancer remains unknown. In the present study, a significant decrease in 5-hmC levels were obserevd in lung cancer tissues compared with the adjacent tissues and the OS of patients with low 5-hmC levels were distinctly lower than patients with high 5-hmC level, which were both in line with the previous reports in HCC, ICC and gastric cancer (8). Clinically, 5-hmC level was significantly related to lymph node metastasis, histological type and tumor size. Furthermore, the 5-hmC level was identified as an independent prognostic factor for NSCLC patients' OS in this cohort. Thus, it can be concluded that low levels of 5-hmC promote the NSCLC progression.

In 2009, two reports $(18,19)$ published in Science, indicated that 5 -hmC exists as prevalently as 5-mC in mammalian genomic DNA, and 5-hmC is now generally accepted as 'the sixth base' of genomes of higher organisms (20). Similar to 5-mC, 5-hmC not only exhibits its universal and dynamic characteristics, but also participates in a number of important regulations of cellular functions including tumorigenesis and tumor progression (21). In the present study, the level of 5-hmC in NSCLC and their corresponding paired normal lung tissues was detected by immunohistochemistry and dot-blot semi-quantitative analysis. Furthermore, it was demonstrated that the proportion of low 5-hmC level was less frequent in adenocarinoma compared with the other types of NSCLC, and there were varying expression levels of 5-hmC in lung cancer and normal tissues. Generally, the 5-hmC levels were lower in NSCLC samples.

The relationship between the 5-hmC level and pathological characteristics of NSCLC were further analyzed. Consitent with other reports (22), in the present study, low levels of 5-hmC were more common in patients with lymph node metastases, high histological types and large tumor sizes, which are recognized prognostic factors for lung cancer (23). The proportion of low 5-hmC level in NSCLC patients with lymph node metastases was markedly higher than those patients without lymph node metastases, as well as the histological types and tumor sizes. Moreover, for the association between the 5-hmC levels and prognostic factors of lung cancer the analytic results demonstrated that low levels of 5-hmC was associated with the poor prognosis of NSCLC. The multivariate analyses demonstrated that low levels of 5-hmC may be an independent prognostic factor in NSCLC.

In summary, the present study demonstrated that the 5-hmC levels were significantly lower in NSCLC tissues compared with the corresponding adjacent cancer tissues, and revealed that low levels of 5-hmC may be an important and potential prognostic biomarker to screen patients with an unfavorable prognosis.

\section{Acknowledgements}

The present work was supported by the National Natural Science Foundation of China (grant nos. 81201834, 81372313 and 81401876), the Fund of Shanghai Municipal Health Bureau (grant nos. 20124324 and 20134322), and the project for the development of young teachers (grant no. JJF152065).

\section{References}

1. Jemal A, Siegel R, Xu J and Ward E: Cancer statistics, 2010. CA Cancer J Clin 60: 277-300, 2010.

2. Qiu X, Liang Y, Sellers RS, Perez-Soler R and Zou Y: Aerosol azacytidine inhibits orthotopic lung cancers in mice through Its DNA demethylation and gene reactivation effects. PLoS One 9: e109874, 2014.

3. Goldstraw P, Crowley J, Chansky K, Giroux DJ, Groome PA, Rami-Porta R, Postmus PE, Rusch V and Sobin L; International Association for the Study of Lung Cancer International Staging Committee; Participating Institutions: The IASLC lung cancer staging project: Proposals for the revision of the TNM stage groupings in the forthcoming (seventh) edition of the TNM Classification of malignant tumours. J Thorac Oncol 2: 706-714, 2007.

4. Liutkevičiūtė Z, Kriukienè E, Ličytė J, Rudytė M, Urbanavičiūtė $\mathrm{G}$ and Klimašauskas S: Direct decarboxylation of 5-carboxylcytosine by DNA C5-methyltransferases. J Am Chem Soc 136: 5884-5887, 2014

5. Delhommeau F, Dupont S, Della Valle V, James C, Trannoy S, Massé A, Kosmider O, Le Couedic JP, Robert F, Alberdi A, et al: Mutation in TET2 in myeloid cancers. N Engl J Med 360: 2289-2301, 2009

6. Wu H, Wu X, Shen L and Zhang Y: Single-base resolution analysis of active DNA demethylation using methylase-assisted bisulfite sequencing. Nat Biotechnol 32: 1231-1240, 2014.

7. Li Y, Córdoba-Cañero D, Qian W, Zhu X, Tang K, Zhang H, Ariza RR, Roldán-Arjona T and Zhu JK: An AP endonuclease functions in active DNA dimethylation and gene imprinting in Arabidopsis (corrected). PLoS Genet 11: e1004905, 2015.

8. Dong ZR, Zhang C, Cai JB, Zhang PF, Shi GM, Gao DM, Sun HC, Qiu SJ, Zhou J, Ke AW and Fan J: Role of 5-hydroxymethylcytosine level in diagnosis and prognosis prediction of intrahepatic cholangiocarcinoma. Tumour Biol 36: 2763-2771, 2015.

9. Kudo Y, Tateishi K, Yamamoto K, Yamamoto S, Asaoka Y, Ijichi H, Nagae G, Yoshida H, Aburatani H and Koike K: Loss of 5-hydroxymethylcytosine is accompanied with malignant cellular transformation. Cancer Sci 103: 670-676, 2012.

10. Gu J, Ding JY, Lu CL, Lin ZW, Chu YW, Zhao GY, Guo J and Ge D: Overexpression of CD88 predicts poor prognosis in non-small-cell lung cancer. Lung Cancer 81: 259-265, 2013.

11. Sica GL and Gal AA: Lung cancer staging: Pathology issues. Semin Diagn Pathol 29: 116-126, 2012.

12. Travis WD, Brambilla E, Nicholson AG, Yatabe Y, Austin JH, Beasley MB, Chirieac LR, Dacic S, Duhig E, Flieder DB et al; WHO Panel: The 2015 World Health Organization Classification of Lung Tumors: Impact of Genetic, Clinical and Radiologic Advances Since the 2004 Classification. J Thorac Oncol 10: 1243-1260, 2015.

13. Ke AW, Shi GM, Zhou J, Huang XY, Shi YH, Ding ZB, Wang XY, Devbhandari RP and Fan J: CD151 amplifies signaling by integrin $\alpha 6 \beta 1$ to PI3K and induces the epithelial-mesenchymal transition in HCC cells. Gastroenterology 140: 1629-1641.e15, 2011.

14. Zhao GY, Ding JY, Lu CL, Lin ZW and Guo J: The overexpression of $14-3-3 \zeta$ and Hsp27 promotes non-small cell lung cancer progression. Cancer 120: 652-663, 2014

15. Hattman S: The first recognized epigenetic signal: DNA glucosylation of T-even bacteriopages. Epigenetics 4: 150-151, 2009.

16. Yin R, Mo J, Lu M and Wang H: Detection of human urinary 5-hydroxymethylcytosine by stable isotope dilution HPLC-MS/MS analysis. Anal Chem 87: 1846-1852, 2015.

17. Yang Q, Wu K, Ji M, Jin W, He N, Shi B and Hou P: Decreased 5-hydroxymethylcytosine $(5-\mathrm{hmC})$ is an independent poor prognostic factor in gastric cancer patients. J Biomed Nanotechnol 9: 1607-1616, 2013.

18. Kriaucionis S and Heintz N: The nuclear DNA base 5-hydroxymethylcytosine is present in Purkinje neurons and the brain. Science 324: 929-930, 2009. 
19. Tahiliani M, Koh KP, Shen Y, Pastor WA, Bandukwala $\mathrm{H}$, Brudno Y, Agarwal S, Iyer LM, Liu DR, Aravind L and Rao A: Conversion of 5-methylcytosine to 5-hydroxymethylcytosine in mammalian DNA by MLL partner TET1. Science 324: 930-935, 2009.

20. Moen EL, Mariani CJ, Zullow H, Jeff-Eke M, Litwin E, Nikitas JN and Godley LA: New themes in the biological functions of 5-methylcytosine and 5-hydroxymethylcytosine. Immunol Rev 263: 36-49, 2015.
21. Ye $\mathrm{C}$ and Li L: 5-hydroxymethylcytosine: A new insight into epigenetics in cancer. Cancer Biol Ther 15: 10-15, 2014.

22. Ulas A, Turkoz FP, Silay K, Tokluoglu S, Avci N, Oksuzoglu B and Alkis N: A laboratory prognostic index model for patients with advanced non-small cell lung cancer. PLoS One 9: e114471, 2014.

23. Campobasso O, Andrion A, Mancuso M, De Simone M and Ribotta M: The postoperative survival in pulmonary carcinomas depending on the histological type and stage. Ann Osp Maria Vittoria Torino 31: 9-24, 1989 (In Italian). 